\title{
Growth and characterization of epitaxial magnesium ferrite thin films
}

O. Mauit, K. Fleischer, B. O’Dowd, D. Mullarkey and I. V. Shvets

School of Physics and Centre for Research on Adaptive Nanostructures and Nanodevices (CRANN), Trinity College Dublin, the University of Dublin, Dublin 2, Ireland

\begin{abstract}
Epitaxial magnesium ferrite thin films have been grown by molecular beam epitaxy (MBE) on $\mathrm{MgO}(100)$. Growth conditions such as substrate temperature and growth rates were optimized. By using different characterization techniques, structural, electrical and optical properties of the films were studied as a function of $\mathrm{Mg}$ content. In particular, we highlight the importance of the growth rate on the actual $\mathrm{Mg} / \mathrm{Fe}$ ratio in the film.
\end{abstract}




\section{Introduction}

Spinel ferrites are a class of compounds with the general formula of $\mathrm{MFe}_{2} \mathrm{O}_{4}$ (where $\mathrm{M}=\mathrm{Mn}$, $\mathrm{Co}, \mathrm{Ni}, \mathrm{Zn}, \mathrm{Mg}$. etc.). There is a near infinite pool of options for partially substituting cations into this spinel structure (see Fig. 1). This can be represented by the chemical formula $\mathrm{M}_{\delta} \mathrm{Fe}_{3-}$ ${ }_{\delta} \mathrm{O}_{4}$ where $\delta$ can range from 0 to 3 , and even multiple alternate cations can be simultaneously inserted, e.g, $\mathrm{Mn}_{0.5} \mathrm{Co}_{0.5} \mathrm{Fe}_{2} \mathrm{O}_{4}$. Spinel ferrite materials have already been widely used in devices such as transformer cores and microwave magnetic devices for more than fifty years [1, 2]. Much research and development in the field of spinel ferrites is still on-going, ranging from studying the basic properties of these materials to their applications. From a more fundamental perspective, epitaxial ferrite films have provided a model system to study the effect of modified super-exchange interaction and cation redistribution [3]. Among the investigated ferrites, magnesium ferrite $\left(\mathrm{MgFe}_{2} \mathrm{O}_{4}, \mathrm{MFO}\right)$ is a soft magnetic n-type semiconductor with a partially inverse spinel structure. The typical degree of inversion is 0.9 but can vary depending on the preparation conditions $[4,5]$. MFO possesses good chemical stability, and its band gap of $\sim 2.0 \mathrm{eV}$ makes it a suitable candidate for a wide range of applications in heterogeneous catalysis, adsorption, sensors, lithium-ion batteries, and photo electrochemical water splitting [6-10]. Moreover, it has a high Curie temperature, making it interesting for spintronic applications. To date, most studies on $\mathrm{MgFe}_{2} \mathrm{O}_{4}$ have focused on its different morphological varieties, such as nanoparticles [6-10] or nanopillars [11]. However, less attention has been paid to epitaxial $\mathrm{MgFe}_{2} \mathrm{O}_{4}$ thin films even though they are of great interest from both fundamental and practical perspectives. These thin films, when fabricated with high epitaxial quality and synthesized at lower temperatures than bulk ceramics, often show significantly different physical properties compared to bulk material $[12,13]$. The physical properties of

magnesium ferrite strongly depend on the site location of the $\mathrm{Mg}^{2+}$ ions, while the growth techniques as well as processing conditions also play an important role [14-19].Among the 
various thin film growth techniques, molecular beam epitaxy (MBE) is very attractive for deposition of high crystalline quality thin film oxides. By varying the individual evaporator temperatures the molecular flux of different species can be accurately controlled, providing a way to alter the composition and doping profile in thin spinel ferrite films. MBE grown magnetite and cobalt ferrite thin films have previously been shown to have excellent magnetic properties [20-23]. In contrast there have been few attempts to grow magnesium ferrite thin films using MBE $[5,19,24]$. None of these reports have studied the magnesium ferrite thin film physical properties as a function of deposition conditions in detail. In a previous study carried out by some of us, certain properties of epitaxial $\mathrm{MgFe}_{2} \mathrm{O}_{4}$ films using the same growth technique and substrate have already been studied [19]. Newly available data, in particular on the stoichiometry of films at reduced growth rate and the optical properties of the films, led to this more comprehensive study, where we will demonstrate that a reduced growth rate primarily alters the film composition rather than solely the thin film strain as previously assumed. Here we will discuss this behavior in terms of the growth process and growth temperature.

\section{Experimental details}

A series of $\mathrm{MgFe}_{2} \mathrm{O}_{4}$ films with a thickness of $95 \mathrm{~nm}$ were grown on $\mathrm{MgO}(100)$ oriented single-crystal substrates with a size of $1 \mathrm{~cm}^{2}$. Substrates were first cleaned in an ultrasonic bath for 15 minutes in methanol, isopropanol and acetone subsequently. Prior to deposition they were annealed in-situ at $600^{\circ} \mathrm{C}$ in an oxygen partial pressure of $1.7 \times 10^{-3} \mathrm{~Pa}$ in the Molecular Beam Epitaxy chamber (DCA MBE M600). This system uses e-beam evaporators, where the source material (Kurt.J.Lesker, Iron pellets (EVMFE35QXQ) 99.95\% purity; MgO pieces (EVMMGO3-6MMB) $99.95 \%$ purity) is locally heated by high energy electrons. The flux of the molecular beam was controlled by varying the power applied to the e-beam evaporators, 
while the growth rate was measured by a calibrated quartz crystal oscillator for each source. The individual quartz crystal oscillators have been calibrated at our reference rate of 0.6 and $0.3 \AA / s$ by growing $\mathrm{Fe}_{3} \mathrm{O}_{4}$ and $\mathrm{MgO}$ reference samples respectively. The resulting thickness was measured by X-Ray reflection and the difference between nominal and real thickness is used to adjust the tooling factor of the quartz crystal balance. This calibration procedure is repeated after each vent and/or refill of the e-beam pockets. Metallic Fe and ceramic $\mathrm{MgO}$ were evaporated from separate e-beam evaporators in order to grow $\mathrm{MgFe}_{2} \mathrm{O}_{4}$ films. Each source ( $\mathrm{Fe}$ and $\mathrm{MgO}$ ) has a dedicated port to house a quartz crystal balance, positioned in such a way that it's shielded from the other sources. To grow stoichiometric oxides from metal sources the growth is assisted by an oxygen plasma from an OSPrey ECR-plasma source operated in an oxygen partial pressure of $2.6 \times 10^{-4} \mathrm{~Pa}$ with a current of $30 \mathrm{~mA}$.

To investigate the influence of growth conditions on film properties, the growth rate and substrate temperate were systematically varied (see Table 1). The ratio between the Fe and $\mathrm{MgO}$ flux rate was kept at a constant value (of Fe:Mg=2:1), in order to preserve the nominal cation stoichiometry in the deposited films. Post growth each sample thickness was measured by Xray reflection and observed deviations from the nominally expected thickness were in the range of $3-10 \%$, with the larger deviations occurring for smaller growth rates.

Despite the similar thickness of all films as confirmed by X-ray reflection (XRR), the films are optically different and show a systematic variation in electrical and magnetic properties upon variation of the growth rate. To understand the $\mathrm{MgFe}_{2} \mathrm{O}_{4}$ growth a comprehensive characterization of crystalline quality, chemical composition, optical, and electrical properties was performed. This included high resolution X-ray diffraction (HRXRD), UV-Vis Spectroscopy, X-Ray photoelectron spectroscopy (XPS) and resistance-temperature measurements (RT). 
Crystallographic characterization was performed with a Bruker D8 Advance X-ray diffractometer equipped with a $\mathrm{Cu} \mathrm{K} \mathrm{K}_{\alpha}$ source and a double bounce Ge crystal monochromator. $\Theta / 2 \Theta$ scans were taken after aligning to the $\mathrm{MgO}(200)$ substrate reflex. To assess the in-plane epitaxial strain reciprocal space maps around the $\mathrm{MgO}$ (113) reflex were taken. The resistivity of each film was measured as a function of temperature $(100-300 \mathrm{~K})$ in linear four point probe geometry using gold contact patches deposited in-situ (after film growth) via a shadow mask. The magnetic hysteresis loops of the films were measured using a Quantum Design physical properties measurements system (PPMS) with a vibrating sample magnetometer (VSM) at room temperature with fields up to $2 \mathrm{~T}$. The actual $\mathrm{Mg} / \mathrm{Fe}$ ratio of the $\mathrm{MgFe}_{2} \mathrm{O}_{4}$ films was determined by quantitative XPS in an Omicron Multiprobe XPS system using Al Ka X-rays $(\mathrm{h} v=1486.7 \mathrm{eV})$ with an EA125 U5 analyzer. For ex-situ XPS measurements, all samples were chemically cleaned in acetone and isopropanol with an ultrasonic bath and sputtercleaned using an Ar ion gun operated at $500 \mathrm{eV}$ for 10 minutes with a sputter current of 2$3 \mu \mathrm{A}$ to remove surface carbon and hydroxides formed after exposure to air. Optical properties, in particular the fundamental optical gap were measured by UV-VIS spectrophotometry in a Perkin Elmer Lambda 650S using an integrating sphere in transmission with air as reference.

\section{Results}

\subsection{Crystallographic properties}

Figure 2 shows the $\Theta / 2 \Theta$ diffraction pattern for the (200) Bragg reflections of the $\mathrm{MgO}$ substrate and the (400) thin film reflection for films grown with a substrate temperature of (a) $300^{\circ} \mathrm{C}$ and (b) $350^{\circ} \mathrm{C}$. Patterns for all evaporation rates (R1-R6) are shown stacked for clarity. The strong peak at $42.917^{\circ}$ originates from the $\mathrm{MgO}$ substrate. The second, smaller, broad peak close to substrate peak (indicated by the coloured arrows) is the thin film peak. Addi- 
tional structures around $43^{\circ}$ and $43.3^{\circ}$ originate from residual $\mathrm{Cu} \mathrm{K}_{\alpha 2}$ radiation and the sample holder respectively.

The thin film peak of $\mathrm{MgFe}_{2} \mathrm{O}_{4}$ (400) is located around $43.18^{\circ}$, consistent with the wellestablished values, indicating an epitaxial growth mode for the films [25]. However the substrate-film peak separation decreases with a decrease in growth rate indicating substantial changes in either thin film composition or strain. The calculated out of plane lattice constants $a_{\perp}$ are given in Fig. 2. The value ranges from $8.374 \AA$ to $8.386 \AA$, a slightly changed value when compared to sintered bulk $\mathrm{MgFe}_{2} \mathrm{O}_{4}(8.387 \AA$, JCPD 00-036-0398) due to the epitaxial constraints placed on the film by the $\mathrm{MgO}$ in-plane lattice constant (see Fig. 3). There are two possible origins for a change of the $a_{\perp}$ lattice parameter: One is, as some of us previously thought, a strain effect due to different growth conditions and film thickness [19], the other a change in the actual $\mathrm{Mg}: \mathrm{Fe}$ ratio of the films. As the thickness of each film that was grown here is the same, it is clear that either the $\mathrm{Mg}$ :Fe ratio is changing in the films, or the variation in growth rate leads to other strain relaxation pathways, e.g. via crystal defects such as stacking faults. To distinguish these cases, reciprocal space maps of the (113) reflex have been analyzed.

Figure 3 clearly shows that the thin films are fully strained with an in plane lattice constant $a_{\|}$ identical to the $\mathrm{MgO}$ substrate. Hence strain relaxation has been ruled out for the observed changes in $a_{\perp}$. In the case of $\mathrm{M}_{\delta} \mathrm{Fe}_{3-\delta} \mathrm{O}_{4}$, the $\mathrm{Mg}^{2+}$ is expected to replace the $\mathrm{Fe}^{2+}$ ions on the B-site for $x<1$ [26]. As the Mg:Fe ratio is further increased some of the Mg must eventually replace the $\mathrm{Fe}^{3+}$. Since the ionic radius of $\mathrm{Mg}^{2+}(0.57 \AA)$ is in between $\mathrm{Fe}^{2+}(0.63 \AA)$ and $\mathrm{Fe}^{3+}$ $(0.49 \AA)$, the replacement of $\mathrm{Fe}^{3+}$ by $\mathrm{Mg}^{2+}$ is expected to increase the unit cell volume and the lattice parameter $a$. The effect is seen amplified in $a_{\perp}$ once the in plane parameter is confined by the substrate. The observed shift in peak position upon growth rate reduction could there- 
fore be indicative of a large change in the $\mathrm{Mg}$ : $\mathrm{Fe}$ ratio within the film, despite the nominally constant ratio in the atomic flux during growth.

\subsection{Film stoichiometry}

The Mg concentration was therefore determined by XPS analyzing the ratio of the areas of the $\mathrm{Mg} 2 \mathrm{p}$ and $\mathrm{Fe}\left(3 \mathrm{p}_{3 / 2}+3 \mathrm{p}_{1 / 2}\right)$ core levels in CasaXPS. To describe the line shape accurately, a Shirley background was subtracted and the peak area determined by least square fitting of three components (one symmetric peak (GL(30)) for the Mg-2p, one symmetric (GL(30)) and one asymmetric (SGL(30)T(1.5) to accurately account for the Fe-3p line shape). The different photoemission cross section of each element and the analyzer transfer function of the instrument was taken into account by the XPS analysis software. Figure 4 shows the dependency of the actual $\mathrm{Mg}$ content on the nominal growth rate. For the different rates $\left(\mathrm{T}_{\mathrm{g}}=300^{\circ} \mathrm{C}: \mathrm{R} 6, \mathrm{R} 4\right.$, $\mathrm{R} 2$, R1) the film stoichiometry is $\mathrm{Mg}_{1.1} \mathrm{Fe}_{1.9} \mathrm{O}_{\mathrm{y}}, \mathrm{Mg}_{1.35} \mathrm{Fe}_{1.65} \mathrm{O}_{\mathrm{y}}, \mathrm{Mg}_{1.5} \mathrm{Fe}_{1.5} \mathrm{O}_{\mathrm{y}}$, and $\mathrm{Mg}_{2} \mathrm{Fe}_{1} \mathrm{O}_{\mathrm{y}}$ respectively. This dramatic change in actual film composition explains the changes in the out of plane lattice constant observed by XRD and has major implications on the electrical and optical properties of the $\mathrm{M}_{\delta} \mathrm{Fe}_{3-\delta} \mathrm{O}_{4}$ films.

\subsection{Electrical and Magnetic measurements}

The fact that the $\mathrm{Mg}$ concentration $\delta$ is found to be higher than $\delta=1$ has interesting implications on the electrical and magnetic properties. Plots of resistivity vs reciprocal temperature are shown in Fig 5. Magnesium ferrite shows n-type conductivity with low electron mobilities best described by the small polaron hopping model $\rho=\mathrm{T} \rho_{0} \exp \left(W / \mathrm{k}_{\mathrm{B}} T\right)[27,28]$. As also reported for epitaxial $\mathrm{Zn}_{\mathrm{x}} \mathrm{Fe}_{3-\mathrm{x}} \mathrm{O}_{4}$ there is very little deviation from a simple activated Arrhenius type behavior $\rho=\rho_{0} \exp \left(E_{a} / \mathrm{k}_{\mathrm{B}} T\right)$ [29]. Figure 5 shows linear fits for both models allowing for extraction of the respective activation energies $\left(E_{\mathrm{a},} W\right)$. Resistivity values for the films 
were found to increase dramatically as the Mg concentration increases. Simple thermovoltage measurements confirm n-type carriers and the Seebeck coefficient was found to be in the range of -85 to $-110 \mu \mathrm{V} / \mathrm{K}$ for samples $\left(\mathrm{R} 6, \mathrm{R} 4, T_{g}=350^{\circ} \mathrm{C}\right)$. Due to the high resistivity of samples grown at R2 and R1 similar measurements were not possible with our setup. Details of the Seebeck setup in use are found in [30]. The room temperature resistivity of the thin film grown at the lowest growth rate (R1) is approximately three orders of magnitude larger than for films grown at the highest rate (R6). The carrier activation energy $E_{a}$ remains similar for samples where $\delta<1.5$, indicating only small changes in the conduction mechanism, but there is a large change in the carrier concentration as $\mathrm{Mg}$ replaces more and more $\mathrm{Fe}^{3+}$. Only for the highest $\mathrm{Mg}$ content does $E_{a}$ change significantly. While for the most stoichiometric sample (R6) the measured temperature dependence is consistent over the whole temperature range, there are deviations from the simple models for the off-stoichiometric samples below $160 \mathrm{~K}$. This is most likely caused by the more defective nature of these films resulting in a non-negligible defect induced conductance, e.g., along grain boundaries.

Magnetization measurements on films with the highest and lowest growth rates are shown in Fig 6. The saturation magnetization, $M_{s}$, measured at room temperature for the films grown at $300^{\circ} \mathrm{C}$ with the highest (R6) and lowest (R1) rate was found to be $106 \pm 6$ and $25 \pm 2 \mathrm{emu} / \mathrm{cm}^{3}$ respectively. The measured magnetization of sample R6 is comparable to the reported bulk compound value [14]. The saturation magnetization for the films decreases with a decrease in growth rate. This is due to the presence of more non-magnetic $\mathrm{Mg}$ in the samples grown at a lower deposition rate. Interestingly, films deposited at a lower rate show an increase in the coercivity and loop squareness $M_{r} / M_{s}$, consistent with the expected increase in lattice disorder as the probability of $\mathrm{Mg}$ replacing $\mathrm{Fe}^{3+}$ on the tetragonal A-site will increase significantly for higher Mg content. Fig. 6a highlights the differences in coercivity and 
remanent magnetization, while Fig. $6 \mathrm{~b}$ illustrates the same overall shape of the magnetization loops.

\subsection{Optical properties}

To determine the optical band gap of the Mg ferrite films UV-VIS spectrophotometry was performed. Transmission measurements quantify the visually different appearance of the thin films, despite their similar thickness. The absorption coefficient $\alpha$ was calculated from transmission measurements using the known thickness values from XRR. A Tauc plot was used to estimate the optical band gap $E_{g}$, assuming a direct allowed optical transition $(\alpha h v \sim(h v$ $\left.\left.E_{g}\right)^{1 / 2}\right)$. The optical gap for different growth rates is plotted in Figure 7, showing that differences in the onset of absorption are linked to the observed stoichiometry changes. No significant differences are observed for films grown at 300 or $350^{\circ} \mathrm{C}$.

\section{Discussion}

Our results indicate that the properties of $\mathrm{MgFe}_{2} \mathrm{O}_{4}$ can be fine-tuned by changing the growth rate resulting in changes in the $\mathrm{Mg} / \mathrm{Fe}$ ratio. The high crystalline quality is confirmed by the diffractogram of the thin films, where only changes in lattice parameter are observed; no dephasing or reduction in crystal size was detected. This is possible due to the small lattice mismatch of the film with the $\mathrm{MgO}$ substrate and the fact that the $\mathrm{Mg}$ content can be further increased by inclusion of $\mathrm{MgO}$ unit cells in the larger $\mathrm{MgFe}_{2} \mathrm{O}_{4}$ and $\mathrm{Fe}_{3} \mathrm{O}_{4}$ unit cells as schematically illustrated in Figures 1 and 8.

The strong dependence of the film stoichiometry on growth rate is a consequence of the complex interactions of the atomic flux of different sources with the molecular and atomic oxygen from the plasma source provided during growth. The cation source flux is measured at a different distance than the source to sample distance, and the temperature of the flux sensor remains constant. A reduction in metallic Fe flux, while maintaining the same oxygen partial 
pressure leads to an effectively higher interaction of atomic Fe with the oxygen background and altered arrival rate as well as adsorption rate at the substrate. The amount of reduction is not linear with distance and hence the readout of the quartz oscillator, located much closer to the source does not reflect these changes in the same way. In contrast, the $\mathrm{MgO}$ when evaporated from ceramic pellets is less likely to interact with the background oxygen as the evaporation is unlikely to break the already present, strong $\mathrm{Mg}-\mathrm{O}$ bonds. Hence reducing the source flux by the same factor for $\mathrm{MgO}$ and $\mathrm{Fe}$ does not necessarily maintain the same $\mathrm{Mg} / \mathrm{Fe}$ ratio arriving and adsorbing at the sample.

Once the substrate temperature is changed a second effect could come into play as the $\mathrm{MgO}$ clusters are less likely to be adsorbed and incorporated. Indeed, the growth rate of $\mathrm{MgO}$ grown from e-beam evaporated $\mathrm{MgO}$ pellets is reduced at high temperatures [31]. Films grown at the same $\mathrm{Fe} / \mathrm{Mg}$ flux ratio and total flux, but at a higher temperature, consequently show a reduced Mg content as well (see Fig. 4a).

Our findings highlight the care required for growing ternary oxides from two different source materials (metal and metal oxide). Once precise stoichiometry is required, even small changes in growth temperature or growth rate will alter the stoichiometry and require recalibration of the flux monitors. On the other hand, this dependency also offers an easy way to reliably alter the stoichiometry or grow samples with stoichiometry gradients by simply altering the growth rate during deposition.

\section{Conclusion}

In conclusion, we have successfully grown magnesium ferrite films by a co-deposition of Fe and $\mathrm{MgO}$ via $\mathrm{MBE}$. Despite a constant nominal $\mathrm{Fe} / \mathrm{MgO}$ flux ratio, the $\mathrm{Mg}$ concentration in the films increases with decreasing evaporation rate, leading to films with controllable magnetic, electrical and optical properties. 


\section{Acknowledgements}

The authors would like to acknowledge financial support by Science Foundation Ireland under grant No. 12/IA/1264, financial support from the Irish Research Council under grant No. GOI/PG/2013/444, as well as the support of the Government of Republic of Kazakhstan under the Bolashak program.

\section{References}

[1] J.L. Snoek, New developments in ferro-magnetic materials, Elsevier, Amsterdam, 1947.

[2] C.L. Hogan, The ferromagnetic faraday effect at microwave frequencies and its applications, Bell System Technical Journal, 31 (1952) 1-31.

[3] Y. Suzuki, Epitaxial spinel ferrite thin films, Annu. Rev. Mater. Res., 31 (2001) 265-289.

[4] S.K. Pradhan, S. Bid, A. Gateshki, V. Petkov, Microstructure characterization and cation distribution of nanocrystalline magnesium ferrite prepared by ball milling, Mater Chem Phys, 93 (2005) 224-230.

[5] J. Cheng, V.K. Lazarov, G.E. Sterbinsky, B.W. Wessels, Synthesis, structural and magnetic properties of epitaxial $\mathrm{MgFe}_{2} \mathrm{O}_{4}$ thin films by molecular beam epitaxy, J Vac Sci Technol B, 27 (2009) 148-151.

[6] S.A. Oliver, R.J. Willey, H.H. Hamdeh, G. Oliveri, G. Busca, Structure and magnetic-properties of magnesium ferrite fine powders, Scripta Metall. Mater., 33 (1995) 1695-1701.

[7] G. Busca, E. Finocchio, V. Lorenzelli, M. Trombetta, S.A. Rossini, IR study of alkene allylic activation on magnesium ferrite and alumina catalysts, J. Chem. Soc. Faraday Transactions, 92 (1996) 4687-4693.

[8] Y. Hou, F. Zuo, A. Dagg, P.Y. Feng, A Three-Dimensional Branched Cobalt-Doped alpha- $\mathrm{Fe}_{2} \mathrm{O}_{3}$ Nanorod/ $\mathrm{MgFe}_{2} \mathrm{O}_{4}$ Heterojunction Array as a Flexible Photoanode for Efficient Photoelectrochemical Water Oxidation, Angew. Chem. Int. Ed., 52 (2013) 1248-1252.

[9] Y. Pan, Y. Zhang, X.P. Wei, C.L. Yuan, J.L. Yin, D.X. Cao, G.L. Wang, $\mathrm{MgFe}_{2} \mathrm{O}_{4}$ nanoparticles as anode materials for lithium-ion batteries, Electrochimica Acta, 109 (2013) 89-94.

[10] N.R. Su, P. Lv, M.J. Li, X.L. Zhang, M.H. Li, J.S. Niu, Fabrication of $\mathrm{MgFe}_{2} \mathrm{O}_{4}-\mathrm{ZnO}$ heterojunction photocatalysts for application of organic pollutants, Mater. Lett., 122 (2014) 201-204.

[11] D.H. Kim, N.M. Aimon, X.Y. Sun, C.A. Ross, Compositionally Modulated Magnetic Epitaxial Spinel/Perovskite Nanocomposite Thin Films, Adv Funct Mater, 24 (2014) 2334-2342.

[12] Y. Yamamoto, H. Tanaka, T. Kawai, Appearance of magnetic blocking temperature in zinc magnesium ferrite thin films, J. Magnet. Mag. Mater., 261 (2003) 263-268.

[13] L. Yang, L. Yin, Y.C. Zhang, Y.L. Lu, F. Li, Facile preparation of magnesium ferrite film via a singlesource precursor route, Chem. Lett., 36 (2007) 1462-1463.

[14] A.H. Morrish, Physical principles of Magnetism, Wiley-IEEE, New York, 2001.

[15] B. Viswanathan, V.R.K. Murthy, Ferrite materials : science and technology, Springer ; New Delhi : Narosa, 1990.

[16] M. Zimnol, A. Graff, H. Sieber, S. Senz, S. Schmidt, R. Mattheis, D. Hesse, Structure and morphology of $\mathrm{MgFe}_{2} \mathrm{O}_{4}$ epitaxial films formed by solid state reactions on $\mathrm{MgO}(100)$ surfaces, Solid State Ionics, 101 (1997) 667-672.

[17] K.S. Kim, P. Muralidharan, S.H. Han, J.S. Kim, H.G. Kim, C.I. Cheon, Influence of oxygen partial pressure on the epitaxial $\mathrm{MgFe}_{2} \mathrm{O}_{4}$ thin films deposited on $\mathrm{SrTiO} 3$ (100) substrate, J Alloy Compd, 503 (2010) 460-463.

[18] R.K. Gupta, F. Yakuphanoglu, Epitaxial growth of $\mathrm{MgFe}_{2} \mathrm{O}_{4}$ (111) thin films on sapphire (0001) substrate, Mater. Lett., 65 (2011) 3058-3060. 
[19] H.C. Wu, O. Mauit, C.O. Coileain, A. Syrlybekov, A. Khalid, A. Mouti, M. Abid, H.Z. Zhang, M. Abid, I.V. Shvets, Magnetic and transport properties of epitaxial thin film $\mathrm{MgFe}_{2} \mathrm{O}_{4}$ grown on $\mathrm{MgO}$ (100) by molecular beam epitaxy, Scientific Reports, 4 (2014).

[20] S.K. Arora, R.G.S. Sofin, I.V. Shvets, M. Luysberg, Anomalous strain relaxation behavior of $\mathrm{Fe}_{3} \mathrm{O}_{4} / \mathrm{MgO}$ (100) heteroepitaxial system grown using molecular beam epitaxy, J Appl. Phys., 100 (2006).

[21] R. Ramos, S.K. Arora, I.V. Shvets, Anomalous anisotropic magnetoresistance in epitaxial $\mathrm{Fe}_{3} \mathrm{O}_{4}$ thin films on $\mathrm{MgO}(001)$, Phys Rev B, 78 (2008).

[22] S.A. Chambers, R.F.C. Farrow, S. Maat, M.F. Toney, L. Folks, J.G. Catalano, T.P. Trainor, G.E. Brown, Molecular beam epitaxial growth and properties of $\mathrm{CoFe}_{2} \mathrm{O}_{4}$ on $\mathrm{MgO}(001)$, J. Magnet. Mag. Mater., 246 (2002) 124-139.

[23] G.E. Sterbinsky, J. Cheng, P.T. Chiu, B.W. Wessels, D.J. Keavney, Investigation of heteroepitaxial growth of magnetite thin films, J Vac Sci Technol B, 25 (2007) 1389-1392.

[24] D.S. Lee, J.S. Wang, D.K. Modak, Y.S. Liu, C.L. Chang, G. Chern, The magnetic properties of strained and relaxed $\mathrm{Fe}_{3-\mathrm{x}} \mathrm{Mg}_{\mathrm{x}} \mathrm{O}_{4}$ ferrite films on $\mathrm{MgO}(001)$ and $\mathrm{SrTiO}_{3}(001)$ by molecular beam epitaxy, $J$ Appl. Phys., 101 (2007) 3.

[25] K.H.J. Buschow, Handbook of magnetic materials. Vol.8, North-Holland, Amsterdam ; Oxford, 1995.

[26] O. Alejos, C. de Francisco, J.M. Munoz, P. Hernandez-Gomez, C. Torres, A.G. Arias, Magnetic disaccommodation in ferrites with nonmagnetic divalent substitutions, Jpn J Appl Phys 1, 40 (2001) 2245-2250.

[27] P.V. Reddy, R. Satyanarayana, T.S. Rao, Electrical-Conduction in Magnesium Ferrite, J Mater Sci Lett, 3 (1984) 847-849.

[28] Q.Y. Pan, K. Koumoto, H. Yanagida, High-Temperature Electrical-Conduction in Magnesium Ferrite, Nippon Seram Kyo Gak, 95 (1987) 1079-1083.

[29] D. Venkateshvaran, M. Althammer, A. Nielsen, S. Geprags, M.S.R. Rao, S.T.B. Goennenwein, M. Opel, R. Gross, Epitaxial $\mathrm{Zn}_{\mathrm{x}} \mathrm{Fe}_{3-\mathrm{x}} \mathrm{O}_{4}$ thin films: A spintronic material with tunable electrical and magnetic properties, Phys Rev B, 79 (2009).

[30] L. Farrell, K. Fleischer, D. Caffrey, D. Mullarkey, E. Norton, I.V. Shvets, Conducting mechanism in the epitaxial p-type transparent conducting oxide Cr2O3:Mg, Phys Rev B, 91 (2015).

[31] M.D. Losego, H.S. Craft, E.A. Paisley, S. Mita, R. Collazo, Z. Sitar, J.P. Maria, Critical examination of growth rate for magnesium oxide $(\mathrm{MgO})$ thin films deposited by molecular beam epitaxy with a molecular oxygen flux, J Mater Res, 25 (2010) 670-679. 


\section{Figure captions}

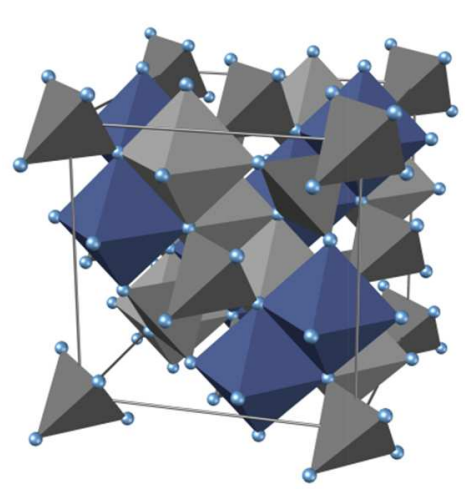

$\mathrm{Fe}_{3} \mathrm{O}_{4}$

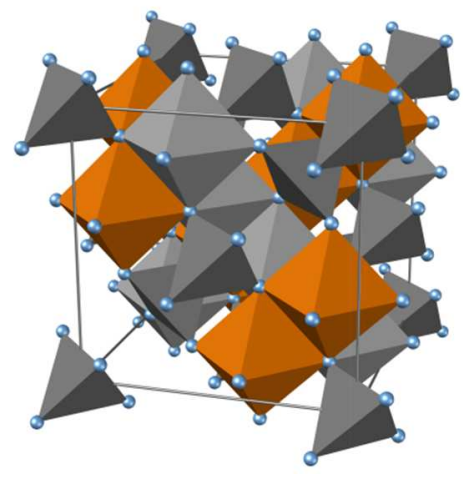

$\mathrm{MgFe}_{2} \mathrm{O}_{4}$

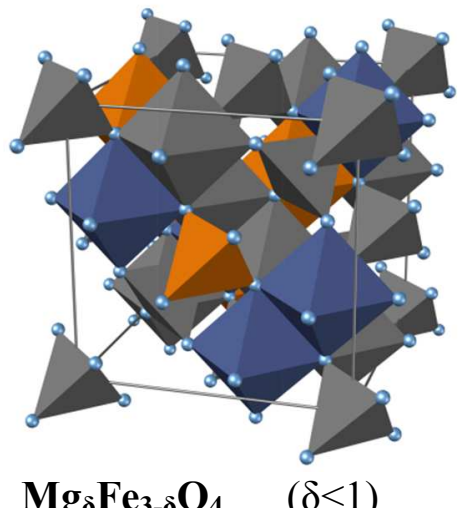

$(\delta<1)$

Figure 1: Crystal structure of magnetite $\left(\mathrm{Fe}_{3} \mathrm{O}_{4}\right)$, magnesium ferrite $\mathrm{MgFe}_{2} \mathrm{O}_{4}$ and nonstoichiometric $\mathrm{Mg}_{\delta} \mathrm{Fe}_{3-\delta} \mathrm{O}_{4}$. The spinel tetrahedral A-sites are occupied by $\mathrm{Fe}^{3+}$ while the octahedral B-sites are occupied by $\mathrm{Fe}^{3+}$ and $\mathrm{Fe}^{2+}$ (dark blue). In ideal $\mathrm{MgFe}_{2} \mathrm{O}_{4}$ the $\mathrm{Mg}^{2+}$ replaces all $\mathrm{Fe}^{2+}$ octahedral sites (orange). Which B-site is occupied by $\mathrm{Mg}^{2+}$ and which with $\mathrm{Fe}^{3+}$ can either be random as illustrated or show a long range order. Additional site disorder can also lead to $\mathrm{Mg}^{2+}$ occupying the tetrahedral A-sites as illustrated for the non-stoichiometric $\mathrm{Mg}_{\delta} \mathrm{Fe}_{3-\delta} \mathrm{O}_{4}$.
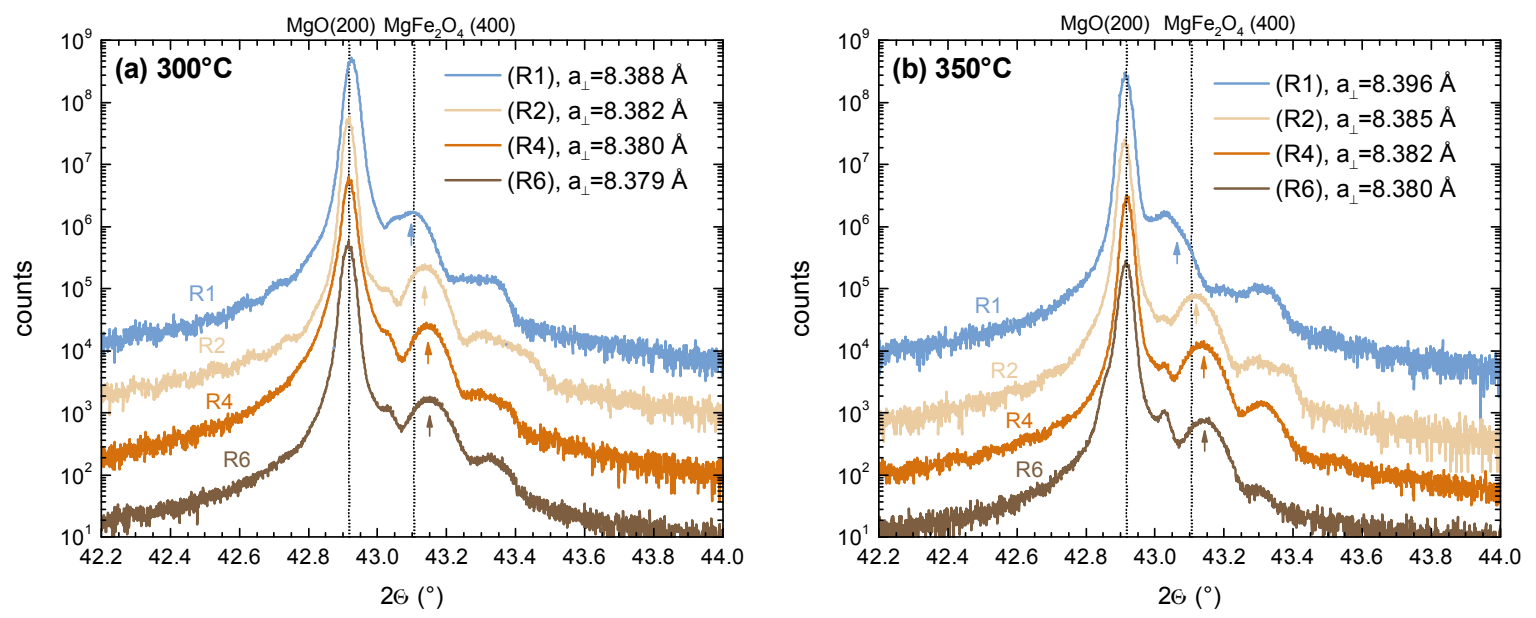

Figure 2: X-ray $\Theta / 2 \Theta$ diffraction scans of films with different growth rates at a substrate temperature of $300^{\circ} \mathrm{C}(\mathrm{a})$ and $350^{\circ} \mathrm{C}(\mathrm{b})$. 


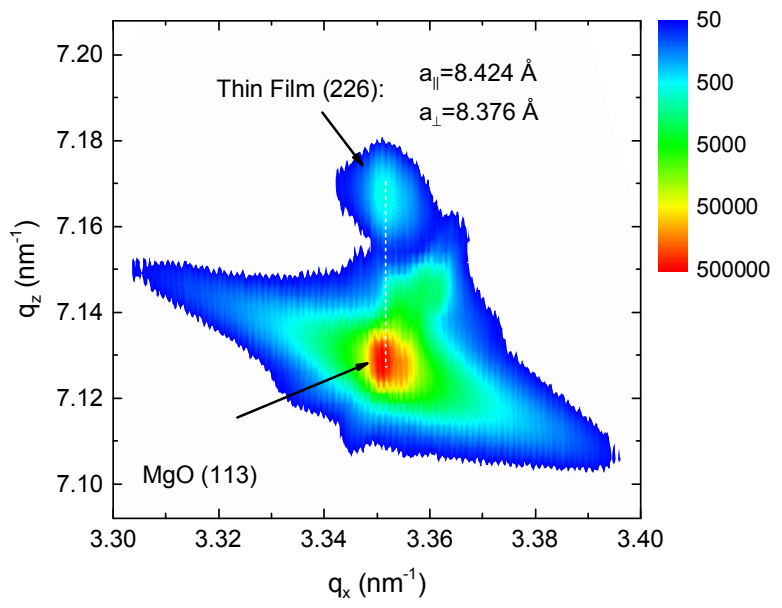

Figure 3: X-ray reciprocal space map shown for one sample $\left(\mathrm{R} 4,300^{\circ} \mathrm{C}\right)$. The thin film inplane lattice constant $a_{\|}$is fully confined by the $\mathrm{MgO}$ substrate as indicated by the dashed line.
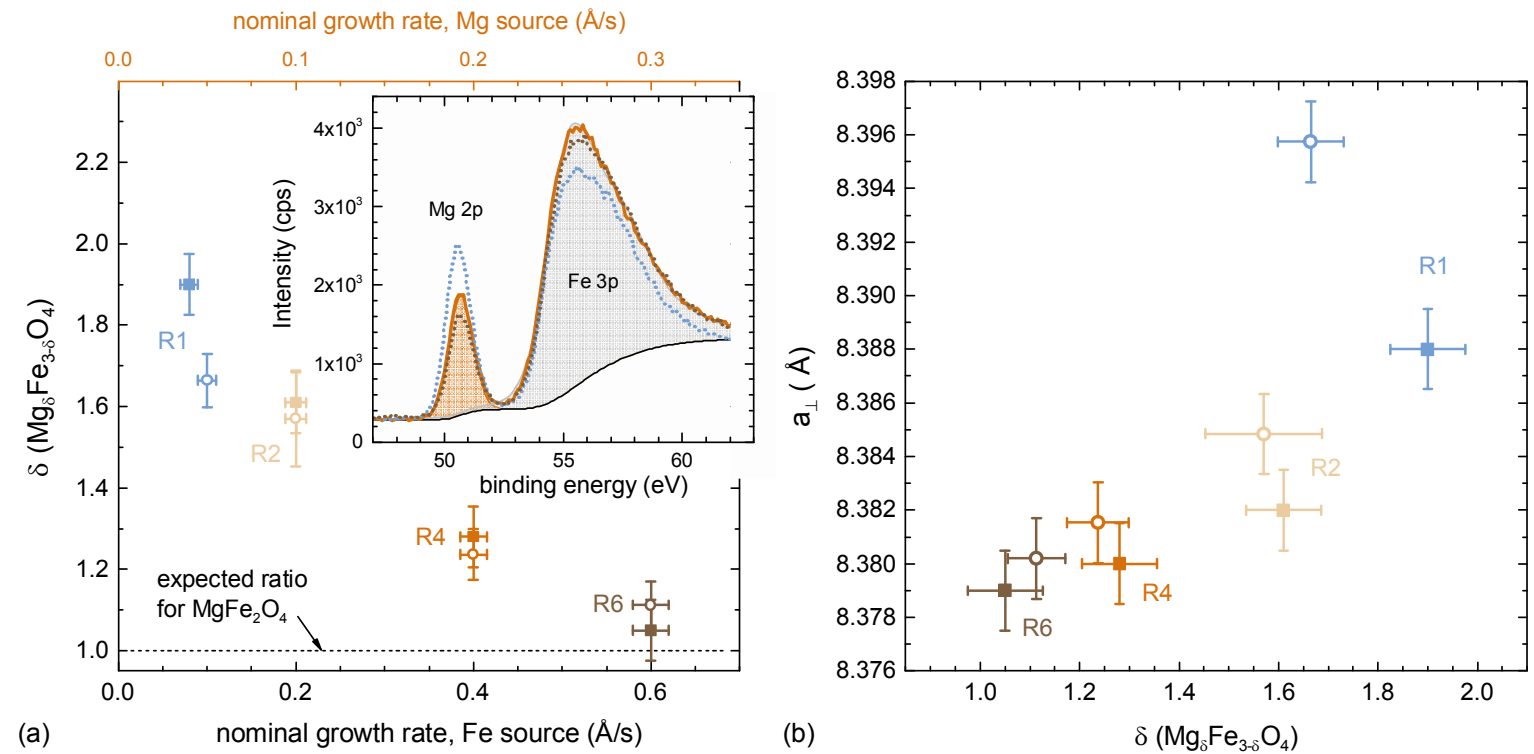

Figure 4: (a) Nominal flux vs measured Mg:Fe ratio of the films. The inset shows the XPS data for R1, R4, R6 $\left(350^{\circ} \mathrm{C}\right)$ and peak deconvolution for R4. (b) shows the correlation between composition and $a_{\perp}$. Closed squares are used for samples grown at $300^{\circ} \mathrm{C}$, open circles for those grown at $350^{\circ} \mathrm{C}$. 

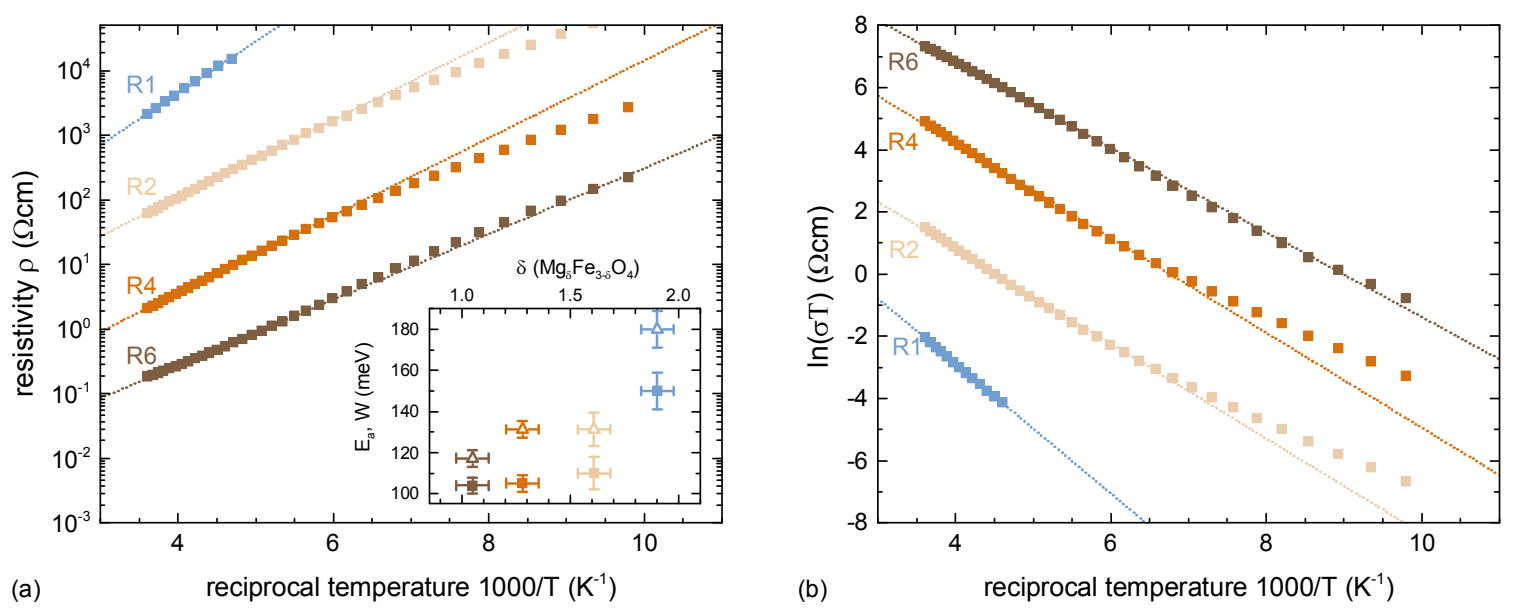

Figure 5: (a) Resistivity vs reciprocal temperature plots for films grown at different rates at $300^{\circ} \mathrm{C}$. The inset shows the extracted carrier activation energy $E_{a}$ ( $\mathbf{\square}$, simple activation model) and $W(\Delta$, small polaron hopping) from linear fits in the range from $160-300 \mathrm{~K}$ (b) shows the same data plotted as $\ln (\mathrm{T} / \rho)$.
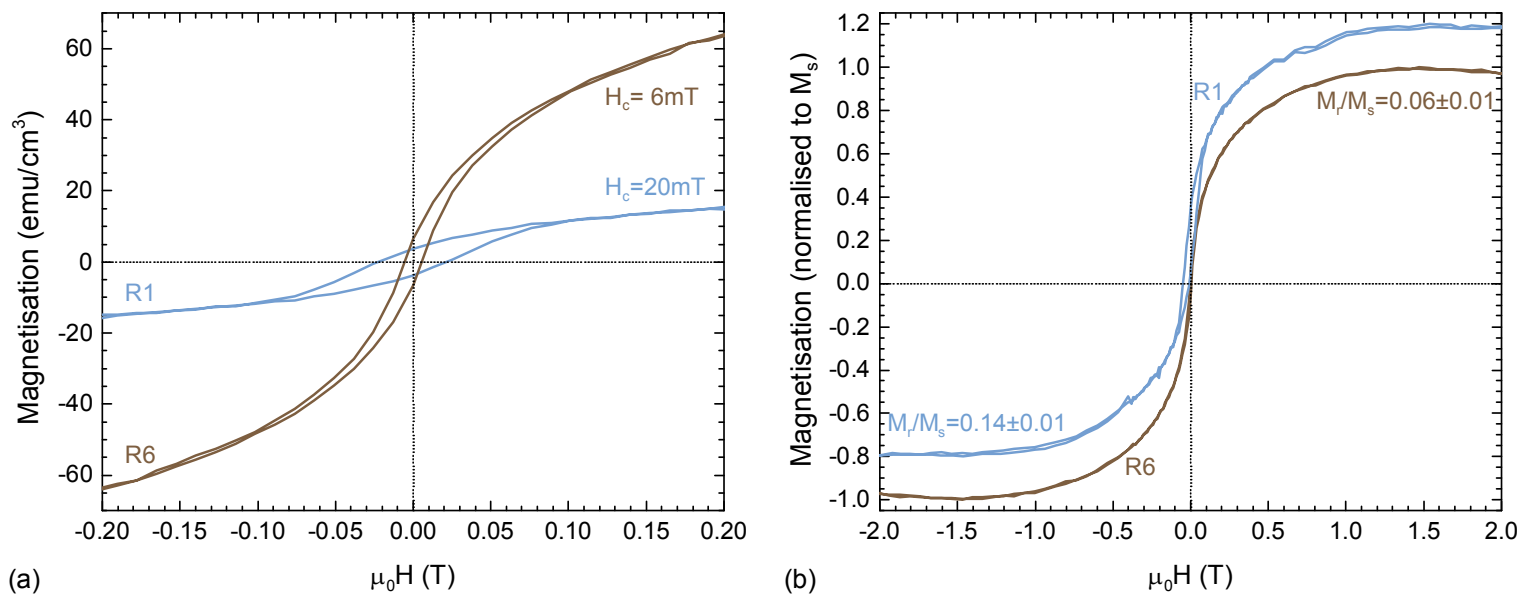

Figure 6: Magnetic hysteresis loops of films grown at $300^{\circ} \mathrm{C}$ with highest (R6) and lowest (R1) growth rate measured at room temperature with an in-plane magnetic field. The right panel shows data normalized to $M_{s}$. The dataset for R1 has been offset by 0.2 for clarity. 


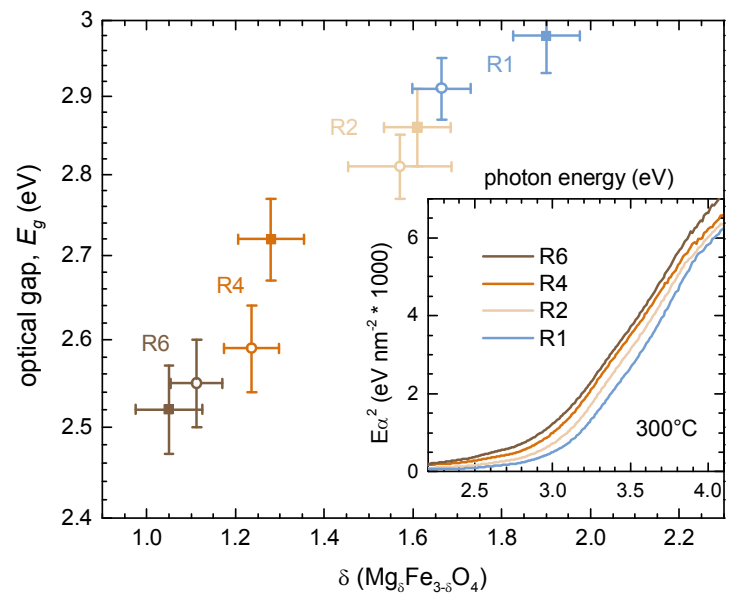

Figure 7: Variation of the optical gap as a function of film composition for samples grown at $300^{\circ} \mathrm{C}$ (closed symbols) and $350^{\circ} \mathrm{C}$ (open symbols). The inset shows the Tauc plot calculated from transmission measurements and known sample thickness from XRR. $E_{g}$ values are estimated by linear fits of $E \alpha^{2}$

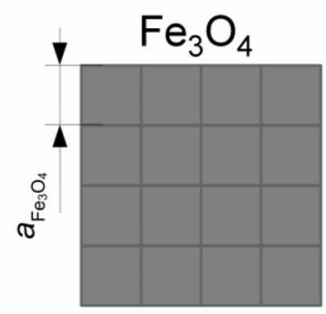

$\delta=0$

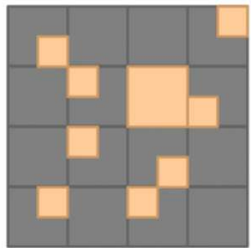

$0<\delta<1$

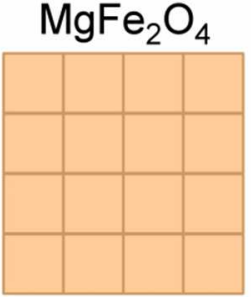

$\delta=1$

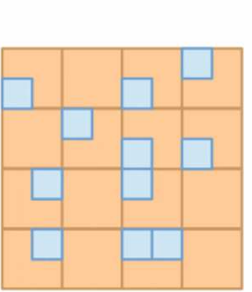

$\delta>1$

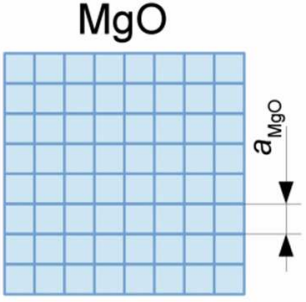

Figure 8: Schematic illustration of how non-stoichiometric $\mathrm{Mg}_{\mathrm{x}} \mathrm{Fe}_{3-\mathrm{x}} \mathrm{O}_{4}$ can be maintained in high crystalline quality due to local sublattice substitution. 
Tables

\begin{tabular}{c|c|c|c|c}
$\mathrm{T}_{\mathrm{s}}$ & $\begin{array}{c}\text { Growth rate } \\
(\AA / \mathrm{s})\end{array}$ & $\begin{array}{c}\text { Growth rate } \\
(\AA / \mathrm{s})\end{array}$ & $\begin{array}{c}\text { Growth rate } \\
(\AA / \mathrm{s})\end{array}$ & $\begin{array}{c}\text { Growth rate } \\
(\AA / \mathrm{s})\end{array}$ \\
\hline$\left.{ }^{\circ} \mathrm{C}\right)$ & $\mathbf{R 6}$ & $\mathbf{R 4}$ & $\mathbf{R 2}$ & $\mathbf{R} 1$ \\
\hline \multirow{2}{*}{$\mathbf{3 0 0}$} & $\mathrm{R}_{\mathrm{Fe}}=0.6 \pm 0.02$ & $\mathrm{R}_{\mathrm{Fe}}=0.4 \pm 0.015$ & $\mathrm{R}_{\mathrm{Fe}}=0.2 \pm 0.012$ & $\mathrm{R}_{\mathrm{Fe}}=0.08 \pm 0.01$ \\
& $\mathrm{R}_{\mathrm{MgO}}=0.3$ & $\mathrm{R}_{\mathrm{MgO}}=0.2$ & $\mathrm{R}_{\mathrm{MgO}}=0.1$ & $\mathrm{R}_{\mathrm{MgO}}=0.04$ \\
\hline \multirow{2}{*}{$\mathbf{3 5 0}$} & $\mathrm{R}_{\mathrm{Fe}}=0.6 \pm 0.02$ & $\mathrm{R}_{\mathrm{Fe}}=0.4 \pm 0.015$ & $\mathrm{R}_{\mathrm{Fe}}=0.2 \pm 0.012$ & $\mathrm{R}_{\mathrm{Fe}}=0.1 \pm 0.01$ \\
& $\mathrm{R}_{\mathrm{MgO}}=0.3$ & $\mathrm{R}_{\mathrm{MgO}}=0.2$ & $\mathrm{R}_{\mathrm{MgO}}=0.1$ & $\mathrm{R}_{\mathrm{MgO}}=0.05$
\end{tabular}

Table 1: Lists the different substrate growth temperatures and nominal individual source evaporation rates used for growth of the films. The nominal rates refer to the readings of the quartz oscillators for each source. Each was calibrated at R6, by growing individual binary $\mathrm{Fe}_{3} \mathrm{O}_{4}$ and $\mathrm{MgO}$ test samples using a single source only. Their thickness was measured post growth by XRR and appropriate tooling factors for the quartz balance have been calculated. The indicated errors for the iron growth rate are based on the measured deviations of measured individual film thickness (XRR) from the nominal thickness based on the quartz balance reading. 